\title{
Fitness Assessment as an Anti-Aging Marker: A Narrative Review
}

\author{
Francisco J Amaro-Gahete ${ }^{1,2^{*}}$, Alejandro De La O ${ }^{1}$, Lucas Jurado-Fasoli ${ }^{1}$, Manuel J Castillo ${ }^{1}$ and Angel Gutiérrez ${ }^{1}$ \\ ${ }^{1}$ Department of Medical Physiology, School of Medicine, University of Granada, Spain \\ ${ }^{2}$ PROmoting FITness and Health through Physical Activity Research Group (PROFITH), Department of Physical Education and Sports, University of Granada, Spain
}

*Corresponding author: Francisco J. Amaro-Gahete, Department of Medical Physiology, School of Medicine, University of Granada, Spain, Tel: +34 697287022 ; Email: amarof@ugr.es

Rec date: December 12, 2017; Acc date: December 19, 2017; Pub date: Decemeber 22, 2017

Copyright: (c) 2017 Amaro-Gahete FJ, et al. This is an open-access article distributed under the terms of the Creative Commons Attribution License, which permits unrestricted use, distribution, and reproduction in any medium, provided the original author and source are credited.

\begin{abstract}
Aging is a natural, physiological, and inevitable process, but it can be also influenced. Although aging is not a disease, it has several characteristics that could indicate so, such as a functional decline at different levels, which may determine clinical manifestations, and it is associated with several disease processes. Consequently, it is essential to create and adopt strategies to delay the aging process. Nowadays, any strategy adopted without including physical exercise seems inconceivable. Recent studies published in relation to this population have shown that the maintenance of acceptable levels of physical fitness is associated with the prevention of many of premature aging consequences, good rates of health, and quality of life of the person. cardiorespiratory fitness and muscular strength (as physical fitness components) are excellent life expectancy and quality of life predictors. Therefore, reaching a good fitness level is the most powerful clinical method to prevent and delay the aging process. Not only their years to live increase, but also their quality, with health and without diseases or mobility dependence.
\end{abstract}

Keywords: Aging; Physical activity; Health; Cardiorespiratory fitness; Muscular strength

\section{Introduction}

One major concern of humans has been to live a long life in good physical and mental conditions, and free of diseases. Aging is not a disease, it is a natural and physiological, progressive, and unavoidable process, but it can be influenced. The aging process is accompanied by a functional decline at different levels. At advanced stages it gives clinical manifestations, and finally, death [1].

Today, people live longer, and aging, as a health problem, affects a growing percentage of the population. It implies addressing the problem with several strategies in order to minimize its effects and avoid its consequences. In this context, a new concept has appeared: "successful aging" [1]. This concept refers to slowing down the functional decline and preventing diseases produced by aging. In this sense, the aim would not be to add years to life, but to add life to years [2]. That is not to prolong life, but to living a full and active life for as long as possible.

To achieve this goal, it is essential to create and adopt strategies to slow down the aging process. Among these strategies, it is imperative to be physically and mentally active, as well as self-sufficient and socially integrated [3]. It is well known that regular physical exercise practice has a fundamental role in this process. Previous studies suggested that doing physical exercise with an adequate intensity and duration could contribute to maintain or even improve the level of fitness, producing powerful anti-aging effects [3]. After that, many studies related to this topic have been published. Thus, the main aim of this review was to update the role of physical fitness as an anti-aging treatment, particularly bearing in mind the measurement of physical fitness as a diagnostic marker of health and biological age.

\section{Literature Review}

\section{Physical fitness components}

Physical fitness is the ability to do physical activity and/or physical exercise using most of the body structures and functions involved in body movements such as the musculoskeletal, cardiorespiratory, hemato-circulatory, endocrine-metabolic system, etc. [3]. Physical fitness integrates several components: (i) cardiorespiratory fitness, (ii) muscular strength, (iii) neuromuscular factors, (iv) body composition, and (v) other factors that include coordination, static and dynamic balance, flexibility, posture, and reaction time [4].

\section{Changes in physical fitness throughout human life span}

Physical fitness is an excellent marker of exercise performance. It is well known that humans suffer a progressive physiological and functional decline (10\% per decade). A previous study showed that the maximum functional capacity occurs between the ages of 20 and 30 approximately, and the clinical manifestations of functional failure occur when $80 \%$ of the functional capacity has been depleted [5]. We can estimate that, in well conditions, excellent health could be maintained until the age of 100 . Two decades later, the exhaustion of functional capacity would be generalized. Reducing the slowdown of the functional capacity to $8 \%$ to $9 \%$ would be a real and effective antiaging therapy. Consequently, measuring the level of physical fitness as a method to determine the functional capacity, health status, expectancy, and quality of life is of great importance [6].

\section{Cardiorespiratory fitness as a health predictor}

Cardiorespiratory fitness is the most important component of physical fitness, and maximum oxygen uptake $\left(\mathrm{VO}_{2} \mathrm{max}\right)$ is the physiological variable which has defined it both traditionally [7] and nowadays [8]. The $\mathrm{VO}_{2}$ max can be measured with indirect calorimetry 
through a maximal or submaximal test with a gas analyzer, as well as with laboratory and field tests $[9,10]$. Some studies clearly show that $\mathrm{VO}_{2}$ max is a powerful predictor of all-cause mortality (especially of cardiovascular diseases) in both healthy men and women of different ages $[11,12]$, and this correlation is independent of different factors such as alcohol, tobacco, or metabolic syndrome [13-15].

A recent review showed that people with high cardiorespiratory fitness have a lower mortality risk (45\% less) for any type of cancer, when compared to individuals with a low level of cardiorespiratory fitness [16]. Lakoski et al. confirmed the existence of an inverse association between cancer mortality (lung and/or colorectal) and high cardiorespiratory fitness in middle-aged adults [17]. Several studies have found a clear association between cardiorespiratory fitness and cognitive impairment. A recent study showed that high levels of cardiorespiratory fitness in early and middle ages are associated with a lower incidence of senile dementia or/and cerebrovascular diseases $[18,19]$. Another study described a relationship between high levels of cardiorespiratory fitness and higher verbal memory and psychomotor speed [20]. Moreover, a negative relationship between high levels of cardiorespiratory condition and the loss of executive function and episodic memory has also been reported [21].

Finally, it has been demonstrated that adequate levels of cardiorespiratory fitness in adults have a strong association with lower public health care costs during the last period of life [22].

\section{Muscular strength as a preventive factor of morbi-mortality and aging}

Muscular strength is a physical fitness parameter that has acquired great relevance in the aging process. Regardless of different factors such as age [23], body fatness, smoking, hypertension [24], or alcohol consumption [25], and even without considering cardiorespiratory fitness [25], an inverse association between muscular strength and mortality risk has been suggested [26].

The aging process implies a slow, but inexorable loss of muscular mass, strength, and functional capacity (sarcopenia and dynapenia). Therefore, the maintenance and improvement of these parameters should be considered as a prevention strategy to fight against the aging process $[27,28]$. The muscular strength level depends on the lean mass [29] and/or the level of physical activity [28]. Consequently, a pronounced loss of muscular strength is positively associated with an accelerated aging and an increase of all-cause mortality risk [26]. Sarcopenia, for instance, is a typical syndrome caused fundamentally by the aging process [30]. The maintenance of muscular strength through physical exercises has been described as a factor which can counteract the natural decline of the lean mass and delay the sarcopenia process [31].

Another factor that also influences aging acceleration is osteoporosis. This process is especially prevalent in postmenopausal women [32], who have traditionally experimented more bone fractures than men [33]. A specific study has shown a positive relationship between hip fractures in osteoporosis population and the risk of morbidity and mortality for all-causes [34]. In addition, another study found a positive relationship between bone mineral density and muscular strength in knee extensor strength and hand grip values [35]. Therefore, it is important to maintain and increase muscular strength as an anti-aging therapy and to fight against the osteopenia process.
On the other hand, recent studies have shown that skeletal muscle has an endocrine and metabolic function related to chronic systemic inflammation [36]. The skeletal muscle produces myokines which are involved in the lipolysis process, improving insulin sensitivity and contributing to the muscle hypertrophy process [37]. An adequate production of myokines is necessary for the metabolic regulation related to obesity, insulin resistance, atherosclerosis, neurodegenerative process, and tumoral diseases [38,39]. Therefore, the loss of lean body mass (associated with the loss of muscular strength) may predispose the development of metabolic diseases such as insulin resistance, diabetes mellitus type II, or metabolic syndrome [27,29], and premature mortality [25] associated to the aging process.

\section{Body composition as a health biomarker in aging}

Body composition is considered an important health biomarker associated with the development or prevention of several diseases [3]. It is well known that the aging process is characterized by an increase in the body fat mass and a decrease in the lean body mass [40].

It has been found that the overweight and obesity prevalence rates increase during the aging process. In fact, it has been estimated that $37 \%$ of men and $42 \%$ of women are obese in the USA [41]. This fact is a public health problem due to a body mass index $>30 \mathrm{~kg} / \mathrm{m} 2$, which is positively associated with aging related diseases [42]. Body fat mass is strongly associated with a higher risk of suffering different chronic diseases (cardiovascular disease, diabetes, and/or cancer) [43]. Furthermore, it contributes to a reduction of the functional capacity $[44,45]$ and, consequently, to the acceleration of the aging process.

Another important factor to consider is body fat mass distribution. Several studies have found that central adiposity (android distribution) is strongly associated with the appearance of cardiovascular diseases in comparison with gynoid distribution [46].

The loss of muscular strength is faster than the loss of lean body mass, suggesting a significant decrease in muscle quality. Therefore, it is essential to investigate strategies which increase muscle quality during the aging process in addition to maintaining or increasing the lean body mass in order to prevent or delay functional impairment as an anti-aging therapy [47].

Adiposity and sarcopenia are two factors that contribute to the decline of the functional capacity and personal autonomy in the elderly. Its synergistic effects are known as sarcopenic obesity. This pathology is associated with an accelerated aging process [48] and greater prevalence of several diseases such as atherosclerosis, diabetes type II, or metabolic syndrome [49].

\section{Other determinants of fitness}

There are other factors that can be included as part of physical fitness. The intra-individual variability of reaction time is considered a functional index of the central nervous system, associating low variability with healthy aging [50]. Coordination (oculomanual/ oculopedical) is also included in the concept of physical fitness. Several studies have shown that coordination training combined with aerobic training increases cognitive performance in the elderly, thus achieving a potent anti-aging effect [51,52]. Finally, low levels of dynamic balance are positively associated with a risk of fractures and falls [53]. Therefore, high levels of this parameter provide a protective role in the prevention of falls in the elderly population [54]. 


\section{Physical Fitness Evaluation}

\section{Cardiorespiratory fitness}

To measure cardiorespiratory fitness, we have to consider different facts: (i) the availability of a physiology lab with technological equipment (gas analyser, ergometer, etc.), (ii) the evaluation purpose, (iii) the patients' characteristics, and (iv) the evaluation context.

\section{Maximum ergometer exercise test (with indirect calorimetry)}

This method is considered the "gold standard" [55] and it can follow specific protocols which depend on the patients' characteristics. All of them start at low intensity and progressively increase over time. The criteria to achieve $\mathrm{VO}_{2}$ max are usually (i) to reach a respiratory exchange ratio $\geq 1.1$, (ii) to observe a plateau in $\mathrm{VO}_{2}$ (change of $<100$ $\mathrm{ml} / \mathrm{min}$ in the last three consecutive 10s stages), (iii) to achieve a heart rate within 10 beats/min of the age-predicted maximal heart rate (208-0.7 $*$ age [56]), and (iv) to obtain a serum lactate $>8.6 \mathrm{Mmol}^{*} \mathrm{~L}-1$ [55]. Different ergometers can be used (treadmill, cycloergometer, remoergometer, etc.).

\section{Submaximum ergometer lab test}

Bruce treadmill test: It is an incremental submaximal treadmill test. It is characterized by its progressive incremental stage with an increase of speed and slope every 3 minutes [57]. The use of the modified Bruce protocol is the most extended currently $[58,59]$.

Single-stage submaximal treadmill walking test: This test starts with a 3 -minute warm-up, walking at $5 \mathrm{~km} / \mathrm{h}$ on a treadmill; the speed is gradually increased until the participants reach a comfortable speed which they can maintain for several minutes. The protocol consists of two parts, walking for 5 minutes. In the first part, the speed must be adjusted between 50 and $70 \%$ of heart rate reserve. The second stage is characterized by an increase of $5 \%$ of the inclination maintaining the same speed. Finally, a 2 -minute recovery stage is carried out at 4 $\mathrm{km}{ }^{\star} \mathrm{h}-1$ [60]. The $\mathrm{VO}_{2}$ max is calculated applying a specific equation [61].

Astrand and rhyming cycle ergometer test: It is done on a cycloergometer, and it calculates the $\mathrm{VO}_{2} \mathrm{max}$ from the heart rate reached after a 6-minute period at different intensities. The stable heart rate for each stage can be calculated through the mean of the last 2 minutes of each stage. If the difference is higher than 5 beats ${ }^{\star}$ minute- 1 , the stage has to be prolonged one additional minute. The first load is specific for sex and age [62]. This test has been used in recent studies $[63,64]$.

Other submaximum lab tests: (i) Using less frequency on the treadmill: Madder test [65] and Self-Paced Walking test [66]; (ii) On the ergometer: Astrand and Rhyming Cycle Ergometer test [62], YMCA test [67], Hollman Cycle Ergometer test [68]; (iii) On the step: Astrand and Rhyming Step test [62], Nagle Step test [69].

\section{Indirect field tests}

The 2-km walk-test (UKK test): It consists in walking at a comfortable and constant speed for 2 kilometres as fast as possible without running. It is necessary to register the test duration and the final heart rate. We can estimate the $\mathrm{VO}_{2}$ max applying a specific equation, and compare by sex and age using the reference values [70]. It is an easy and feasible test to do in elderly population, and it has been used in recent studies [71].
Rockport one-mile fitness walking test: The aim of the test is to complete 1 mile at maximum speed without running [72]. It has been considered a reference value, and its use is currently widespread $[73,74]$.

The 6-min walk test: It consists in walking during 6 minutes at the maximum speed in order to complete the maximum distance without running [75]. It has been applied in elderly populations to assess cardiorespiratory fitness as a predictor of morbidity and mortality [75-81]. It has been used to assess cardiorespiratory fitness in several recent studies $[82,83]$.

The 20-meter shuttle run test (Test of Montreal, Course Navette or Léger Bucher): It consists in running between two points separated by 20 meters. It is synchronized with an audio tape which includes a software that generates beeps at set intervals. As the test progresses, the time interval decreases until the participant cannot maintain the imposed intensity. The starting speed is $8.5 \mathrm{~km}^{\star} \mathrm{h}^{-1}$, and it increases 0.5 $\mathrm{km}^{\star} \mathrm{h}^{-1}$ each stage [84]. The $\mathrm{VO}_{2}$ max can be estimated applying a specific equation [85]. It has been used to asses cardiorespiratory fitness in several studies $[86,87]$.

The 3-minute YMCA step test: It is a submaximal step test. The participant has to step up and down a specific step following an imposed rhythm produced by a metronome ( 96 pulses per minute) for 3 minutes. We can estimate the $\mathrm{VO}_{2} \mathrm{max}$ introducing the final heart rate after the effort applying a specific equation by sex and age [88]. It has been used in some recent studies $[89,90]$.

\section{Muscular strength}

Muscular strength has several dimensions, but in elderly people we can consider two predominantly: (i) "Maximum strength", which is evaluated at a specific instant, and b) (ii) "Endurance strength", which is evaluated using a submaximal load in different situations [91].

\section{Maximum strength}

Isokinetic dynamometry test: It is considered the gold standard method performed in lab conditions. It is based on the realization of specific movements with an established load at a constant speed. It has shown a direct relationship between isokinetic strength in the lower limbs and lower risk of all-cause mortality [92].

Strength assessment by linear encoders: A linear encoder is a dynamometer which allows to obtain variables such as power and mechanical work, force, or speed. The main advantages compared with $1 \mathrm{RM}$ test are that the linear encoder provides valid and reliable values and that it also reduces injury risk [93].

Hand grip test: It is a manual dynamometry which is commonly used as a health marker in elderly population [94]. The starting position is standing and holding a manual dynamometer, which has been regulated and adapted previously, with one hand [95]. The arm has to be separated from the body and the maximum strength must be applied without arm flexion. Two attempts are allowed in each hand, and the sum of the maximum levels are considered the valid measure.

$1 \mathrm{RM}$ test: It is considered the gold standard in non-lab situations [96]. It is defined as the maximum weight that can be lifted from a particular exercise on one attempt [97]. The results can be obtained directly through a specific protocol [98] or indirectly, applying another protocol and using a predictive equation after performing a specific number of repetitions $[99,100]$. 


\section{Muscular endurance}

Linear encoders (fatigue curve): In lab conditions, the most commonly used method to measure muscular endurance is doing a strength test with a submaximal load during a pre-established time in order to get a fatigue curve (force-velocity curve) [93].

Bent arm hang test: This test allows to measure the muscular endurance of the upper limb traction muscles. The participant has to be suspended on a bar with a specific hand position. The performance is assessed through the maximum suspended time [91].

Push up test: This test measures the muscular endurance of the upper limb push muscle. The participant has to be in a prone position with 4 supports (feet and hands on the ground). The number of repetitions performed in 30 seconds is considered the test result [91].

\section{Body composition}

The body composition can be measured using lab techniques or field procedures, according to the precision required and the aim established [101,102].

\section{Lab methods}

Computed axial tomography and magnetic resonance: It provides an evaluation of the tissue-system components in vivo. With both techniques, tissue volume can be determined including the adipose tissue (visceral, subcutaneous, and total), muscular tissue, brain, and organs, skin tissue and bone tissues among others [103].

Dual-energy X-ray absorptiometry (DXA): It assesses the amount of fat free mass (bone content and lean mass) and fat mass by X-rays [104].

Densitometry (hydro-densitometry and air displacement pletismography): The body density is the ratio of the body weight (BW) to the body volume. In this way, the body density can easily be calculated from hydro-densitometry. The body density is used to estimate body fat percentage. Air displacement plethysmography is a method based on air displacement and it uses the relationship between pressure and volume to obtain body fat [105].

Total body electric conductance (TOBEC): This method enables the measurement of body composition through the differences encountered in the electrical conductivity. It has a good reproducibility, accuracy, and precision [106].

\section{Field methods}

Anthropometry: Body mass index is the most commonly used index to elucidate health problems related to body composition. However, it only includes weight and height variables, and it does not not consider differences in lean mass, fat mass, or bone content. Nevertheless, it usually has a good correlation with body fat mass [107,108]. Cutaneous folds measure the skinfold thickness as a method to estimate body fat mass [109]. This method cannot calculate visceral mass, being this its main limitation.

Near-infrared interactance: The major constituents of body composition (fat, protein, and water) can be estimated using a diffuse reflectance spectrophotometry by introducing two wavelength signals, one at peak and the other at minimum absorption, for each compartment [105].

Bioelectrical impedance analysis: It is based on the electrical conductance through biological tissues [110]. This method measures the impedance or opposition to the electric flow through the body fluids [111].

\section{Battery test used for physical fitness assessment}

It is necessary to consider the concept of a battery test, since it allows a complete evaluation of the most important physical fitness qualities. These batteries include individual tests, the results of which can provide a general physical fitness value.

The most used battery test to determine physical fitness are:

ALPHA-FIT test battery for Adults, aged 18-69 [112]: It has been used in several recent studies [113-115]. The ALPHA-FIT battery consists on seven tests, which include the assessment of the main components of physical fitness: (i) the $2 \mathrm{~km}$ walk-test for cardiorespiratory fitness, (ii) the hand-grip test, which indicates the upper limb grip value, (iii) the jump-and-reach test, which determines the muscle strength of the lower extremities, (iv) a modified push-up test, which indicates the upper-train strength and trunk-muscle endurance, (v) the one-leg stand test, which measures static balance, and (vi) body mass index and (vii) waist circumference, both to measure body composition. It is recommended to include three additional tests: (i) dynamic sit-up, which indicates trunk-muscle endurance, (ii) shoulder-neck mobility, which shows flexibility, and (iii) figure-of-eight run, for the dynamic balance and agility [112].

Battery senior fitness test: It is one of the most used battery tests to determine physical fitness in senior or elderly population, and it has been applied in several recent studies [116,117]. This battery tries to evaluate the most important factors related to fitness and health: cardiorespiratory fitness, hip and shoulders mobility, hip extensor strength, and the ability to get up and move [118]. The tests included are 1) the 30-second chair test, 2) the arm curl test, 3) the back-scratch test, 4) the chair sit and rest test, 5) the 2-minute step test, 6) the 6minute walk test, 7) the foot up and go test.

Short physical performance battery: It measures the functionality and the fitness condition in the elderly [119]. It includes several specific tests: the side to side test, the semi tandem stand test and tandem stand test, the gait speed walking speed test, and the lower limbs strength test [120]. It has been used in numerous studies in populations over the age of 69 [121].

When we compare all the previous battery tests, it is suggested that "short physical performance battery" is the most recommended taking into account that it presents the higher values in terms of validity, reliability, and accuracy [122].

\section{Conclusion}

The gradual aging of the population in the last decades suggests the importance of the promotion of a healthy aging based on keeping good physical and mental conditions. Although aging involves a progressive loss of functionality, it is possible to delay or attenuate this functional decline, improving health through physical fitness.

It can be argued that maintaining acceptable levels of physical fitness is associated with the prevention of many consequences of premature aging, as well as good health and quality of life.

It is well-known that physical fitness is an excellent predictor of life expectancy and quality of life, being this association stronger when muscular strength parameters are included. The improvement of physical fitness increases the functional capacity related to aging. Thus, 
it is essential to begin with a correct evaluation of the physical fitness, following the standardized methods, and to follow specific exercise programs based of physical activity recommendations.

\section{Acknowledgements}

The study is supported by the Spanish Ministry of Education (FPU14/04172 and FPU15/03960). We are grateful to Ms. Carmen Sainz Quinn for assistance with the English language, and to Borja Martínez-Téllez for his scientific discussion. This study is part of a Ph.D. Thesis conducted in the Biomedicine Doctoral Studies of the University of Granada, Spain.

\section{References}

1. Bloom M, Klein W (2013) Successful aging: Strategies for healthy living. Springer Science and Business Media. Berlin, Germany.

2. Havighurst R (2008) Process of aging: Social and psychological perspectives. Williams RH, Tibbits C, Donohue W (eds), Transaction Publishers, USA.

3. Castillo GM, Ruiz J, Ortega F, Gutiérrez A (2006) Anti-aging therapy through fitness enhancement. Clin Interv Aging 1:213-220.

4. Oja P, Bull F, Fogelholm M, Martin B (2010) Physical activity recommendations for health: What should Europe do? BMC Public Health 10: 10

5. Moody H, Sasser J (1994) Aging: Concepts and controversies. Pine Forge Press, USA

6. Myers J, McAuley P, Lavie C, Despres J, Arena R, et al. (2015) Physical activity and cardiorespiratory fitness as major markers of cardiovascula risk: Their independent and interwoven importance to health status. Prog Cardiovasc Dis 57: 306-314.

7. Fox E (1973) A simple, accurate technique for predicting maximal aerobic power. J Appl Physiol 35: 914-916.

8. Harber M, Kaminsky L, Arena R, Blair S, Franklin B, et al. (2017) Impact of cardiorespiratory fitness on all-cause and disease-specific mortality: advances since 2009. Prog Cardiovasc Dis.

9. Bennett H, Parfitt G, Davison K, Eston R (2016) Validity of submaximal step tests to estimate maximal oxygen uptake in healthy adults. Sport Med 46: 737-750.

10. Stickland MK, Petersen SR, Bouffard M (2003) Prediction of maximal aerobic power from the $20-\mathrm{m}$ multi-stage shuttle run test. Can J Appl Physiol 28: 272-282.

11. Blair SN, Kohl HW, Barlow CE, Paffenbarger RS, Gibbons LW, et al. (1995) Changes in physical fitness and all-cause mortality. A prospective study of healthy and unhealthy men. JAMA 273: 1093.

12. Blair SN, Kohl HW, Paffenbarger RS, Clark DG, Cooper KH, et al. (1989) Physical fitness and all-cause mortality. JAMA 262: 2395.

13. Kokkinos P, Myers J, Kokkinos JP, Pittaras A, Narayan P, et al. (2008) Exercise capacity and mortality in black and white men. Circulation 117: 614-622.

14. Myers J, Prakash M, Froelicher V, Do D, Partington S, et al. (2002) Exercise capacity and mortality among men referred for exercise testing. N Engl J Med 346: 793-801.

15. Kodama S, Saito K, Tanaka S (2009) Cardiorespiratory fitness as a quantitative predictor of all-cause mortality and cardiovascular events in healthy men and women: A meta-analysis. JAMA 301: 2024.

16. Schmid D, Leitzmann MF (2015) Cardiorespiratory fitness as predictor of cancer mortality: A systematic review and meta-analysis. Ann Oncol 26: $272-278$.

17. Lakoski SG, Willis BL, Barlow CE (2015) Midlife cardiorespiratory fitness, incident cancer, and survival after cancer in men. JAMA Oncol 1: 231.

18. DeFina L, Willis B, Radford N, Gao A, Leonard D, et al. (2013) The association between midlife cardiorespiratory fitness levels and later-life dementia. Ann Intern Med 158: 162.
19. Liu R, Sui X, Laditka JN, Church TS, Colabianchi N, et al. (2012) Cardiorespiratory fitness as a predictor of dementia mortality in men and women. Med Sci Sports Exerc 44: 253-259.

20. Zhu N, Jacobs DR, Schreiner PJ (2014) Cardiorespiratory fitness and cognitive function in middle age: The CARDIA study. Neurology 82 : 1339-1346.

21. Hayes SM, Forman DE, Verfaellie M (2016) Cardiorespiratory fitness is associated with cognitive performance in older but not younger adults. Journals Gerontol Ser B Psychol Sci Soc Sci 71: 474-482.

22. Bachmann J, DeFina L, Franzini L, Gao A, Leonard D, et al. (2015) Cardiorespiratory fitness in middle age and health care costs in later life. J Am Coll Cardiol 66: 1876-1885.

23. Ortega FB, Silventoinen K, Tynelius P, Rasmussen F (2012) Muscular strength in male adolescents and premature death: Cohort study of one million participants. BMJ 345: e7279.

24. Artero EG, Lee D, Ruiz JR, Sui X, Ortega FB, et al. (2011) A prospective study of muscular strength and all-cause mortality in men with hypertension. J Am Coll Cardiol 57: 1831-1837.

25. Volaklis K, Halle M, Meisinger (2015) Muscular strength as a strong predictor of mortality: A narrative review. Eur J Intern Med 26: 303-310.

26. Fitzgerald S, Barlow C, Kampert J, Morrow J, Jackson A, et al. (2004) Muscular fitness and all-cause mortality: Prospective observations. J Phys Act Heal 1: 7-18.

27. Srikanthan P, Karlamangla A (2011) Relative muscle mass is inversely associated with insulin resistance and prediabetes. Findings from the third national health and nutrition examination survey. J Clin Endocrinol Metab 96: 2898-2903.

28. Williams MA, Haskell WL, Ades PA, Amsterdam EA, Bittner V, et al. (2007) Resistance exercise in individuals with and without cardiovascular disease: 2007 update: A scientific statement from the American Heart Association Council on Clinical Cardiology and Council on Nutrition, Physical Activity, and Metabolism. Circulation 116: 572-584.

29. Atlantis E, Martin S, Haren M, Taylor A, Wittert G (2009) Inverse associations between muscle mass, strength, and the metabolic syndrome. Metabolism 58: 1013-1022.

30. Jentoft A, Baeyens J, Bauer J (2010) Sarcopenia: European consensus on definition and diagnosis. Report of the European Working Group on Sarcopenia in Older People. Age Ageing 39: 412-423.

31. Marty E, Liu Y, Samuel A, Or O, Lane J (2017) A review of sarcopenia: enhancing awareness of an increasingly prevalent disease. Bone 105: 276-286.

32. Tella S, Gallagher J (2014) Prevention and treatment of postmenopausal osteoporosis. J Steroid Biochem Mol Biol 142: 155-170.

33. Svedbom A, Hernlund E, Ivergard M, Compston J, Cooper C, et al. (2013) Osteoporosis in the European Union: A compendium of country-specific reports. Arch Osteoporos 8: 137.

34. Ryg J, Rejnmark L, Overgaard S, Brixen K, Vestergaard P (2009) Hip fracture patients at risk of second hip fracture: A nationwide populationbased cohort study of 169,145 cases during 1977-2001. J Bone Miner Res 24: 1299-1307.

35. Schwarz P, Jorgensen N, Nielsen B, Laursen AS, Linneberg A, et al. (2014) Muscle strength, power and cardiorespiratory fitness are associated with bone mineral density in men aged 31-60 years. Scand J Public Health 42: 773-779.

36. Beiter T, Hoene M, Prenzler F, Mooren F, Steinacker J, et al. (2015) Exercise, skeletal muscle and inflammation: are-binding proteins as key regulators in inflammatory and adaptive networks. Exerc Immunol Rev 21: 42-57.

37. León H, Melo C, Ramírez J (2012) Role of the myokines production through the exercise. J Sport Heal Res 4: 157-166.

38. Brandt C, Bente K, Pedersen B (2010) The role of exercise-induced myokines in muscle homeostasis and the defense against chronic diseases. Biomed Res Int.

39. Yoon J, Kim J, Song P, Lee T, Suh P, et al. (2012) Secretomics for skeletal muscle cells: A discovery of novel regulators? Adv Biol Regul 52: 340-350. 
40. Brady AO, Straight CR, Evans EM (2014) Body composition, muscle capacity, and physical function in older adults: An integrated conceptual model. J Aging Phys Act 22: 441-452.

41. Ogden C, Carroll M, Fryar C, Flegal K (2012) Prevalence of obesity in the United States, 2009-2010. NCHS Data Brief.

42. Schaap L, Koster A, Visser M (2013) Adiposity, muscle mass, and muscle strength in relation to functional decline in older persons. Epidemiol Rev 35: 51-65.

43. Chang S, Beason T, Hunleth J, Colditz G (2012) A systematic review of body fat distribution and mortality in older people. Maturitas 72: 175-191.

44. Hung WW, Ross JS, Boockvar KS, Siu AL (2012) Association of chronic diseases and impairments with disability in older adults: A decade of change? Med Care 50: 501-507.

45. Kalyani RR, Saudek CD, Brancati FL, Selvin E (2010) Association of diabetes, comorbidities, and A1C with functional disability in older adults: results from the National Health and Nutrition Examination Survey (NHANES), 1999-2006. Diabetes Care 33: 1055-1060.

46. Lee M, Wu Y, Fried S (2013) Adipose tissue heterogeneity: Implication of depot differences in adipose tissue for obesity complications. Mol Aspects Med 34: 1-11.

47. Gomes MJ, Felippe MP, Pagan LU, Damatto RL, Diacardia M, et al. (2017) Skeletal muscle aging: Influence of oxidative stress and physical exercise. Oncotarget 8: 20428-20440.

48. Goisser S, Kemmler W, Porzel S, Volkert D, Sieber CC, et al. (2015) Sarcopenic obesity and complex interventions with nutrition and exercise in community-dwelling older persons-a narrative review. Clin Interv Aging 10: 1267-1282.

49. Kohara K (2014) Sarcopenic obesity in aging population: current status and future directions for research. Endocrine 45: 15-25.

50. Hultsch DF, Strauss E, Hunter MA, MacDonald SW (2011) The handbook of aging and cognition. (3rd edn).

51. Voelcker RC, Godde B, Staudinger UM (2010) Physical and motor fitness are both related to cognition in old age. Eur J Neurosci 31: 167-176.

52. Voelcker RC, Godde B, Staudinger UM (2011) Cardiovascular and coordination training differentially improve cognitive performance and neural processing in older adults. Front Hum Neurosci 5: 26.

53. Rubenstein L (2006) Falls in older people: Epidemiology, risk factors and strategies for prevention. Age Ageing 35: 37-41.

54. Cebolla E, Rodacki A, Bento P (2015) Balance, gait, functionality and strength: comparison between elderly fallers and non-fallers. Brazilian J Phys Ther 19: 146-151.

55. Pallarés J, Morán-Navarro R (2012) Propuesta metodológica para el entrenamiento de la resistencia cardiorrespiratoria. J Sport Heal Res 4: 119-136.

56. Tanaka H, Monahan K, Seals D (2001) Age-predicted maximal heart rate revisited. J Am Coll Cardiol 37: 153-156.

57. Bruce R, Kusumi F, Hosmer D (1973) Maximal oxygen intake and nomographic assessment of functional aerobic impairment in cardiovascular disease. Am Heart J 85: 546-562.

58. Welch W, Alexander N, Swartz A, Miller N, Twardzik E, et al. (2017) Individualized estimation of physical activity in older adults with type 2 diabetes. Med Sci Sport Exerc 7: 241-248.

59. Falck RS, Davis JC, Milosevic E, Liu AT (2017) How much will older adults exercise? A feasibility study of aerobic training combined with resistance training. Pilot Feasibility Stud 3: 2-6.

60. Ebbeling CB, Ward A, Puleo EM, Widrick J, Rippe JM (1991) Development of a single-stage submaximal treadmill walking test. Med Sci Sports Exerc 23: 966-973.

61. Mitros M, Gabriel KP, Ainsworth B, Lee C, Herrmann S, et al. (2011) Comprehensive evaluation of a single-stage submaximal treadmill walking protocol in healthy, middle-aged women. Eur J Appl Physiol 111: $47-56$.
62. Astrand PO, Ryhming I (1954) A nomogram for calculation of aerobic capacity (physical fitness) from pulse rate during sub-maximal work. J Appl Physiol 7: 218-221.

63. Høj K, Vinther M, Terkildsen H, Christensen B, Sandbæk A (2017) High prevalence of poor fitness among Danish adults, especially among those with high cardiovascular mortality risk. Eur J Public Health 27: 215.

64. Olsson SJG, Ekblom-Bak E, Ekblom B, Kallings LV, Ekblom O, et al (2017) Association of perceived physical health and physical fitness in two Swedish national samples from 1990 and 2015. Scand J Med Sci Sports.

65. Mader A, Heck H, Hollmann W (1981) Leistung und leistungsbegrenzung des menschlichen organismus, interpretiert am modell thermodynamisch offener systeme. In: Sport an der Grenze Menschl. Leistungsfähigkeit. Springer Berlin Heidelberg. pp: 69-93.

66. Bennell K, Dobson F, Hinman R (2011) Measures of physical performance assessments: Self-Paced Walk Test (SPWT), Stair Climb Test (SCT), Six-Minute Walk Test (6MWT), Chair Stand Test (CST), Timed Up \&amp; Go (TUG), Sock Test, Lift and Carry Test (LCT), and Car Task. Arthritis Care Res (Hoboken) 63: 350-370.

67. Golding L, Myers C, Sinning W (1989) Y'S way to physical fitness. Champaign, IL: Human Kinetics Publishers, Inc. USA.

68. Hollmann W (2001) Development of the concepts of ventilatory and lactate threshold. Sport Med 31: 315-320.

69. Nagle FJ, Balke B, Naughton JP (1965) Gradational step tests for assessing work capacity. J Appl Physiol 20: 745-748.

70. Oja P, Manttari A, Pokki T, Kukkonen-Harjula K, Laukkanen R, et al. (2013) UKK Walk Test: Tester's Guide, UKK Institute, Finland.

71. Alvarez C, Ramirez CR, Martinez C, Castro SM, Cano MJ, et al. (2017) Changes in the heart rate recovery to endurance effort after high intensity interval, strength, and concurrent exercise training in patients with insulin resistance. J Sports Med Phys Fitness 57: 1533-1540.

72. Kline G, Porcari J, Hintermeister R, Freedson P, Ward A, et al. (1987) Estimation of VO2max from a one-mile track walk, gender, age, and body weight. Med Sci Sports Exerc 19: 253-259.

73. Chisati EM, Vasseljen O (2015) Aerobic endurance in HIV-positive young adults and HIV-negative controls in Malawi. Malawi Med J 27: 5-9.

74. Mishra S, Scherer R, Geigle P, Ozlem T, Gotay C, et al. (2012) Exercise interventions on health-related quality of life for cancer survivors. Cochrane Database Syst Rev 8: 26-31.

75. Cahalin L, Pappagianopoulos P, Prevost S, Wain J, Ginns L (1995) The relationship of the 6-min walk test to maximal oxygen consumption in transplant candidates with end-stage lung disease. Chest J 108: 452-459.

76. Casanova C, Cote C, Marin J, Pinto PV, De Torres J, et al. (2008) Distance and oxygen desaturation during the 6-min walk test as predictors of longterm mortality in patients with COPD. Chest J 134: 746-752.

77. Jehn M, Halle M, Schuster T, Hanssen H, Weis M, et al. (2009) The 6-min walk test in heart failure: is it a max or sub-maximum exercise test? Eur J Appl Physiol 107: 317-323.

78. Li A, Yin J, Au J, So H, Tsang T, et al. (2007) Standard reference for the six-minute-walk test in healthy children aged 7 to 16 years. Am J Respir Crit Care Med 176: 174-180.

79. Perera S, Mody S, Woodman R, Studenski S (2006) Meaningful change and responsiveness in common physical performance measures in older adults. J Am Geriatr Soc 54 :743-749.

80. Salzman SH (2009) The 6-min walk test: Clinical and research role, technique, coding, and reimbursement. Chest 135: 1345-1352.

81. Weiglein L, Herrick J, Kirk S, Kirk E (2011) The 1-mile walk test is a valid predictor of $\mathrm{VO}_{2} \max$ and is a reliable alternative fitness test to the 1.5mile run in U.S. Air Force males. Mil Med 176: 669-673.

82. Bernocchi P, Vitacca M, La Rovere MT, Volterrani M, Galli T, et al. (2017) Home-based tele rehabilitation in older patients with chronic obstructive pulmonary disease and heart failure: A randomized controlled trial. Age Ageing pp: 1-7. 
83. De Siqueira M, Mendes BM, Gentil P, Izquierdo M, Fisher J, et al. (2017) There are no no-responders to low or high resistance training volumes among older women. Exp Gerontol 99: 18-26.

84. Leger LA, Mercier D, Gadouryl C, Lambert J (1988) The multistage 20 metre shuttle run test for aerobic fitness. J Sports Sci 6: 93-101.

85. Flouris AD, Metsios GS, Koutedakis Y (2005) Enhancing the efficacy of the 20 m multistage shuttle run test. Br J Sports Med 39: 166-170.

86. Brighenti ZS, Mundwiler J, Schüpbach U, Dieterle T, Wolfer D, et al. (2016) Physical workload and work capacity across occupational groups. PLoS One 11: e0154073.

87. Mundwiler J, Schupbach U, Dieterle T, Leuppi J, Schmidt TA, et al. (2017) Association of occupational and leisure-time physical activity with aerobic capacity in a working population. PLoS One 12: 134-142.

88. Golding L (2000) YMCA fitness testing and assessment manual, Human Kine. USA.

89. Beutner F, Ubrich R, Zachariae S, Engel C, Sandri M, et al. (2015) Validation of a brief step-test protocol for estimation of peak oxygen uptake. Eur J Prev Cardiol 22: 503-512.

90. Androulakis KP, Langdown L, Lewis A, Fisher J, Gentil P, et al. (2017) The effects of exercise modality during additional high-intensity interval training upon aerobic fitness and strength in powerlifting and strongman athletes. J Strength Cond Res.

91. ACSM (2013) ACSM's guidelines for exercise testing and prescription. USA.

92. Buckner S, Loenneke J, Loprinzi P (2015) Lower extremity strength, systemic inflammation and all-cause mortality: Application to the "fat but fit" paradigm using cross-sectional and longitudinal designs. Physiol Behav 149: 199-202.

93. Gonzalez BJ, Sanchez ML (2010) Movement velocity as a measure of loading intensity in resistance training. Int J Sport Med 31: 347-352.

94. Bohannon R (2008) Hand grip dynamometry predicts future outcomes in aging adults. J Geriatr Phys Ther 31: 3-10.

95. Ruiz-Ruiz J, Mesa J, Gutierrez A, Castillo M (2002) Hand size influences optimal grip span in women but not in men. J Hand Surg Am 27: 897-901.

96. Levinger I, Goodman C, Hare D, Jerums G, Toia D, et al. (2009) The reliability of the 1RM strength test for untrained middle-aged individuals. J Sci Med Sport 12: 310-316.

97. Kraemer W, Fry A, Ratamess N, French D (1995) Strength testing: Development and evaluation of methodology. Physiol Assess Hum Fit 2 119-150.

98. Baechle T, Earle R (2008) Essentials of strength training and conditioning. National Strength and Conditioning Association (US).

99. Brzycki M (1993) Strength testing-predicting a one-rep max from repsto-Fatigue. J Phys Educ Recreat Danc 64: 88-90.

100. Wathan D (1994) Load assignment in essentials of strength training and conditioning. In: Essentials Strength Train. Cond., Champaign. pp. 435-439.

101. Duren DL, Sherwood RJ, Czerwinski SA, Lee M, Choh AC, et al. (2008) Body composition methods: Comparisons and interpretation. J Diabetes Sci Technol 2: 1139-1146.

102. Lee SY, Gallagher D (2008) Assessment methods in human body composition. Curr Opin Clin Nutr Metab Care 11: 566-572.

103. Ellis KJ (2000) Human body composition: In vivo methods. Physiol Rev 80: $649-680$

104. Haarbo J, Gotfredsen A, Hassager C, Christiansen C (1991) Validation of body composition by dual energy X-ray absorptiometry (DEXA). Clin Physiol 11: 331-341
105. Wagner D, Heyward V (1999) Techniques of body composition assessment: a review of laboratory and field methods. Res Q Exerc Sport 70: $135-149$.

106. Toomey C, Cremona A, Hughes K, Norton C, Jakeman P (2015) A review of body composition measurement in the assessment of health. 30: 16-32.

107. Mei Z, Grummer-Strawn LM, Pietrobelli A, Goulding A, Goran MI, et al. (2002) Validity of body mass index compared with other bodycomposition screening indexes for the assessment of body fatness in children and adolescents. Am J Clin Nutr 75: 978-985.

108. Thivel D, O’Malley G, Pereira B, Duché P, Aucouturier J (2015) Comparison of total body and abdominal adiposity indexes to dual x-ray absorptiometry scan in obese adolescents. Am J Hum Biol 27: 334-338.

109. Sarría A, Moreno L, Garcí-LIop L, Fleta J, Morellón M, et al. (2007) Body mass index, triceps skinfold and waist circumference in screening for adiposity in male children and adolescents. Acta Paediatr 90: 387-392.

110. Segal KR, Gutin B, Presta E, Wang J, Van Itallie TB (1985) Estimation of human body composition by electrical impedance methods: A comparative study. J Appl Physiol 58: 1565-1571.

111. Fosbol MO, Zerahn B (2015) Contemporary methods of body composition measurement. Clin Physiol Funct Imaging 35: 81-97.

112. Suni J, Husu P, Rinne M (2009) Fitness for health: The ALPHA-FIT test battery for adults aged 18-69. Tester's Manual. Tampere. Finland.

113. Ask T, Magnussen LHL, Skouen JS, Skaar A, Kvale A (2015) Experiences with a brief functional evaluation for employees with musculoskeletal disorders as perceived by the employees and their supervisors. 17: 166-175.

114. Ruth CR, Castro LN (2016) Body composition and body balance in people with intellectual disabilities: A descriptive study. Rev Int Cienc Deporte 12

115. Borràs $\mathrm{P}$, Vidal CJ, Palou $\mathrm{P}$ (2016) High intensity strength training in overweight adults in the workplace: a pilot study. J Phys Educ Heal 5: 35-42.

116. Castro PJ, Aparicio VA, Estévez LF, Álvarez Gallardo IC, Borges CM, et al. (2017) The potential of established fitness cut-off points for monitoring women with fibromyalgia: The Al-Ándalus project. Int J Sports Med 38: 359-369.

117. Zhao Y, Chung P, Tong T (2017) Effectiveness of a balance-focused exercise program for enhancing functional fitness of older adults at risk of falling: A randomised controlled trial of Physical Education. Geriatr Nurs (Minneap) 6.

118. Rikli R, Jones C (2013) Senior fitness test manual. Human Kinetics, USA.

119. Guralnik J, Simonsick E, Ferrucci L, Glynn R, Berkman L, et al. (1994) A short physical performance battery assessing lower extremity function: association with self-reported disability and prediction of mortality and nursing home admission. J Gerontol 49: M85-M94.

120. Fish J (2011) Short physical performance battery. Encycl Clin Neuropsychol 2289-2291.

121. Vasunilashorn S, Coppin A, Patel K, Lauretani F, Ferrucci L, et al. (2009) Use of the short physical performance battery score to predict loss of ability to walk 400 meters: Analysis from the In: CHIANTI study. Journals Gerontol Ser A Biol Sci Med Sci 64: 223-229.

122. Freiberger E, De Vreede P, Schoene D, Rydwik E, Mueller V, et al. (2012) Performance-based physical function in older community-dwelling persons: A systematic review of instruments. Age Ageing 41: 712-721. 